УДК 553.9:549.02

\title{
ОСОБЕННОСТИ МИНЕРАЛЬНОГО СОСТАВА НИЗКОПРОНИЦАЕМЫХ КРЕМНИСТО-ГЛИНИСТЫХ ПОРОД-КОЛЛЕКТОРОВ БЕРЁЗОВСКОЙ СВИТЫ СЕВЕРА ЗАПАДНОЙ СИБИРИ
}

\author{
Ананьева Людмила Геннадьевна ${ }^{1}$, \\ Iga@tpu.ru
}

Дорошенко Александр Александрович2, ssdoro.47@mail.ru, a.doroshenko@nedra.gazprom.ru

\author{
Ильенок Сергей Сергеевич ${ }^{1}$, \\ llenokss@tpu.ru
}

\section{Карымова Яна Олеговна², ya.karymova@nedra.gazprom.ru}

\section{Коровкин Михаил Владимирович1,3, mvk@tpu.ru}

\author{
Максимова Юлия Анатольевна ${ }^{1}$, \\ yam3@tpu.ru
}

\author{
Пестерев Алексей Викторович1, \\ pesterev@tpu.ru
}

\author{
Процкий Олег Николаевич 1 , \\ onp6@tpu.ru
}

\section{Савинова Олеся Вячеславовна 1 logvinenkoov@tpu.ru}

\section{Хрущева Мария Олеговна 3 , masha2904@mail.ru}

\footnotetext{
1 Национальный исследовательский Томский политехнический университет, Россия, 635050, г. Томск, пр. Ленина, 30.

2000 «Газпром ВНИИГАЗ», Россия, 625000, г. Тюмень, ул. Герцена, 70.

3 Национальный исследовательский Томский государственный университет, Россия, 634050, г. Томск, пр. Ленина, 36.
}

\begin{abstract}
Актуальность исследования обусловлена необходимостью развития нефртегазопромышленного комплекса Западной Сибири путём выявления нетрадиционных (в том числе низкопроницаемых) коллекторов и оценки их перспективности вовлечения 8 разработку.

Цель: повышение эффрективности газодобычи путём изучения влияния строения минерального вещества пород на поровое пространство и выявление нетрадиционных коллекторов.

Объекты: сенонские отложения, ввод в разработку которых планируется для поддержания добычи в газовой промышленности. Методы: оптическая и электронная сканирующая микроскопия, рентгеноспектральный и рентгенофрлюоресцентный анализ, инфракрасная спектроскопия, рентгеновская дифракция, анализ фильтрационно-емкостных свойств методом GRI-SMP-200. Результаты. Изучены особенности минерального состава низкопроницаемых кремнисто-глинистых пород-коллекторов берёзовской свиты севера Западной Сибири на примере Медвежьего месторождения. Хемогенно-биогенное происхождение данных осадочных пород подтверждается встречающимися остатками органического материала: спикул губок, раковин радиолярий, моллюсков и др. В структуре породы выявляются мелкие поры, заполненные каолинитом и кварцем, и отдельные зёрна монтмориллонита. Также в виде сфрерических агрегатов встречаются многочисленные фрамбоиды пирита (FeS2), который является аутигенным раннедиагенетическим биоминералом, характерным для восстановительной зоны диагенеза. Показано, что литолого-минералогическим критерием выявления продуктивных зон в нетрадиционных коллекторах Медвежьего месторождения может быть выбран «индекс кристалличности», характеризующий степень преобразования опалкристобалит-тридимитовой фазы (ОКТ-фразы) кремнезёма. Появление кристаллической фразы кварца из нестабильного хемогенно-биогенного аморфного кремнезёма вызывает появление более крупных пустот, увеличивая газонасыщенность и газопроницаемость. Выявление особенностей минерального состава низкопроницаемых пород-коллекторов, влияющих на их фильтрационно-емкостные свойства, позволяет оценить перспективность их вовлечения в разработку месторождения, а также будет способствовать решению главной проблемы, возникающей при эксплуатации преобладающего количества газовых месторождений Западно-Сибирской нефртегазоносной провинции, - продление «жизни» месторождений газа после истощения высокопродуктивных сеноманских отложений.
\end{abstract}

\section{Ключевые слова:}

Породы-коллекторы, квари, опал-кристобалит-тридимитовая фраза, полиморфные модифиикации $\mathrm{SiO}_{2}$, опал-кристобалит-тридимитовая фаза кремнезёма, инфрракрасная спектроскопия, рентгеноструктурный анализ.

\section{Введение}

Интерес к изучению нетрадиционных коллекторов обусловлен современными вызовами нефтегазопромышленного комплекса, связанными с поиском новых источников и эффективности добычи углеводородного сырья. В настоящее время отмечается повышенное внимание к проблеме исследования трудноизвлекаемых запасов углеводородов, выявления не- традиционных (в том числе низкопроницаемых) коллекторов с точки зрения оценки их перспективности вовлечения в разработку.

Снижение добычи газа из сеноманских горизонтов заставило обратить внимание на газоперспективность отложений нижне-березовской подсвиты севера Западной Сибири $[1,2]$. Данные отложения представлены опоками, в различной степени глинистыми, и от- 
носятся к числу нетрадиционных: они характеризуются высокой пористостью (коэффициент пористости достигает 40 \%), но низкой проницаемостью (коэффициент проницаемости обычно менее $0,1 \cdot 10^{-3}$ мкм $^{2}$ ) [3-5]. Такая низкая проницаемость предопределяет и низкие дебиты скважин. Однако необходимая информация для обеспечения проектирования разработки сенонских отложений пока явно недостаточна.

С 2013 г. усилиями ПАО «Газпром» началось бурение специальных скважин, в которых осуществлён отбор керна из сенонских отложений, в частности из отложений газонасыщенной нижнеберёзовской подсвиты Медвежьего, Вынгапуровского и других месторождений. При этом использовались технологии, обеспечившие 100 \% вынос породы из всех интервалов отбора керна.

Поскольку хорошо известно, что свойства породколлекторов нефти и газа в значительной степени зависят от их минерального состава, появилась реальная возможность детального изучения кремнистоглинистых пород сенонских отложений физическими методами исследования в лабораторных условиях. Определение глинистых минералов, влияющих на формирование структуры пустотного пространства и изменение фильтрационно-емкостных свойств пласта в процессе добычи, оказалось возможным с помощью методов рентгеновской дифракции, сканирующей электронной микроскопии, инфракрасной спектроскопии [6-8].

В процессе литификации кремниевого хемогеннобиогенного материала трансформация его структуры сопровождается изменением вещественного состава за счет последовательных реакций растворенияосаждения-перекристаллизации и полиморфных переходов кремнезема: опал-А (аморфный кремнезём) в опал-С (низкотемпературный кристаллический кристобалит) и в опал-СТ (опал-кристобалит-тридимит, так называемую ОКТ-фазу - метастабильную форму кремнезема), а по мере более глубоких преобразований - в кристобалит, тридимит, кварц [9]. Опаловый кремнезем (опал-А) образуется в морской, озерной и геотермальной среде на протяжении геологического времени. Во время диагенеза опал-А обычно превращается в опал-СТ, затем опал-С и, наконец, в кварц [10].

В ряде современных работ [10-12] показано, что наблюдается тесная связь между долей содержания кварца в породе и суммарной долей капилляров и макропор в пустотном пространстве. С увеличением доли содержания кварца в породе закономерно увеличивается и доля наиболее крупных пор в пустотном пространстве, что объясняет вероятный механизм появления данных пор. При кристаллизации исходного губчатого кремнистого осадка (геля кремниевой кислоты) в кварц происходит перераспределение молекул кремнезема к центрам кристаллизации. При этом по периферии зон кристаллизации образуются пустоты более крупных размеров, чем в исходном кремнистом осадке. Таким образом, чем больше вновь образованных кристаллов кварца в породе, тем больше размеры пустот.
С точки зрения пористости, проницаемости, плотности и других свойств горных пород переходная 30на, в которой нестабильный хемогенно-биогенный кремнезем превращается из опала-А в метастабильный опал-СТ, является наиболее стратиграфически неоднородным интервалом, образующимся в результате диагенеза мелкозернистых отложений [13].

Следует отметить, что лучшим основным методом для определения и классификации opal-A, opal-CT и opal-C является метод рентгеновской дифракции (XRD) [14-17], наряду с которым метод инфракрасной спектроскопии успешно применяется для определения кристаллических модификаций кремнезёма [18-21]. По сути, главной задачей при определении фазовых разновидностей кремнезёма явилось определение кристаллической фазы кварца как основного минералогического индикатора перспективности породы-коллектора.

В данной работе методами сканирующей электронной микроскопии, рентгеновской дифракции, инфракрасной (ИК) спектроскопии исследовались образцы кремнисто-глинистых пород, отобранных из кернового материала скважин, пробуренных на Медвежьем месторождении.

\section{Методика исследования}

Изучение образцов кремнисто-глинистых пород проводилось с помощью оптического полнофункционального стереомикроскопа Carton DSZT44 с окулярной видеокамерой HDC-20 (окуляры DSW увеличение $10 x / 23.0)$ и электронного сканирующего микроскопа: Hitachi 3400N (c разрешением 3 нм) с энергодисперсионным преобразователем EDX Bruker (X Flash 4010) для определения элементного состава микрозёрен породы.

Фазовые модификации кремнезёма определялись на дифрактометре XPert PRO специальной программой с выводом данных в цифровой форме [22]. Рентгенограммы снимались с шагом около 0,02 в интервале 5...70 град. $2 \Theta$ с вращением 30 об/мин и выдержкой 0,1 сек в точке под рентгеновским $\mathrm{CuK \alpha -}$ излучением. Для исследований из образцов были приготовлены тонкорастёртые (менее 2 мкм) навески, которые затем спрессовали в «таблетку» по методике, изложенной в работе [17].

Спектры ИК-поглощения регистрировались на спектрофотометре IR Prestige-21 фирмы «Shimadzu» c преобразованием Фурье (FTIR-8400S) в интервале $300 \ldots 4000 \mathrm{~cm}^{-1}$ с разрешением $0,001 \mathrm{~cm}^{-1}$ (FT-IR), с помощью программного обеспечения IRsolution. Исследуемый образец (массой 0,5 мг) растирался в агатовой ступке до фракции менее 2 мкм и смешивался с порошком $\mathrm{KBr}$ марок ОЧ или ЧДА, и прессовался в прозрачные тонкие диски $[8,19]$.

Для анализа фильтрационно-емкостных свойств низкопроницаемых коллекторов такого типа использовалась методика, разработанная Gas Research Institute (GRI). Для определения проницаемости дробленые образцы, массой 30 г, помещались в специальную камеру установки SMP-200. Далее в камере с помощью газа (гелия) создавалось давление порядка 
200 psi, после чего регистрировалась кривая падения давления в течение 2000 с, на основании анализа полученной кривой определялось значение проницаемости образца в камере. Так как анализ проводится на дробленом образце, то полученная в ходе эксперимента проницаемость является матричной, то есть не учитывалось влияние естественной трещиноватости.

\section{Экспериментальные результаты и обсуждение}

Образцы кремнисто-глинистых пород-коллекторов Медвежьего месторождения представляют собой тонкозернистую породу (рис. 1), на поверхности которой визуально не выделяются крупные поровые каналы или отчётливо наблюдаемые пустоты. При исследовании на сканирующем электронном микроскопе обнаруживаются мелкие поры, заполненные каолини- том и кварцем (рис. 2), а также отдельные зёрна монтмориллонита (рис. 5), что подтверждается результатами исследований методами рентгеновской дифракции (XRD) и инфракрасной спектроскопии (FT-IR) [23]. В породах встречаются многочисленные фрамбоиды пирита, представляющие собой сферические агрегаты (рис. 3, 4). Фрамбоидальный пирит $\left(\mathrm{FeS}_{2}\right)$ является аутигенным раннедиагенетическим биоминералом, характерным для восстановительной зоны диагенеза. Развитие фрамбоидов пирита и их скоплений приурочено главным образом к зонам осадков с высоким содержанием биогенных компонентов [24]. Это является принципиальным фактом для оценки условий образования и преобразования пород-коллекторов Медвежьего месторождения.

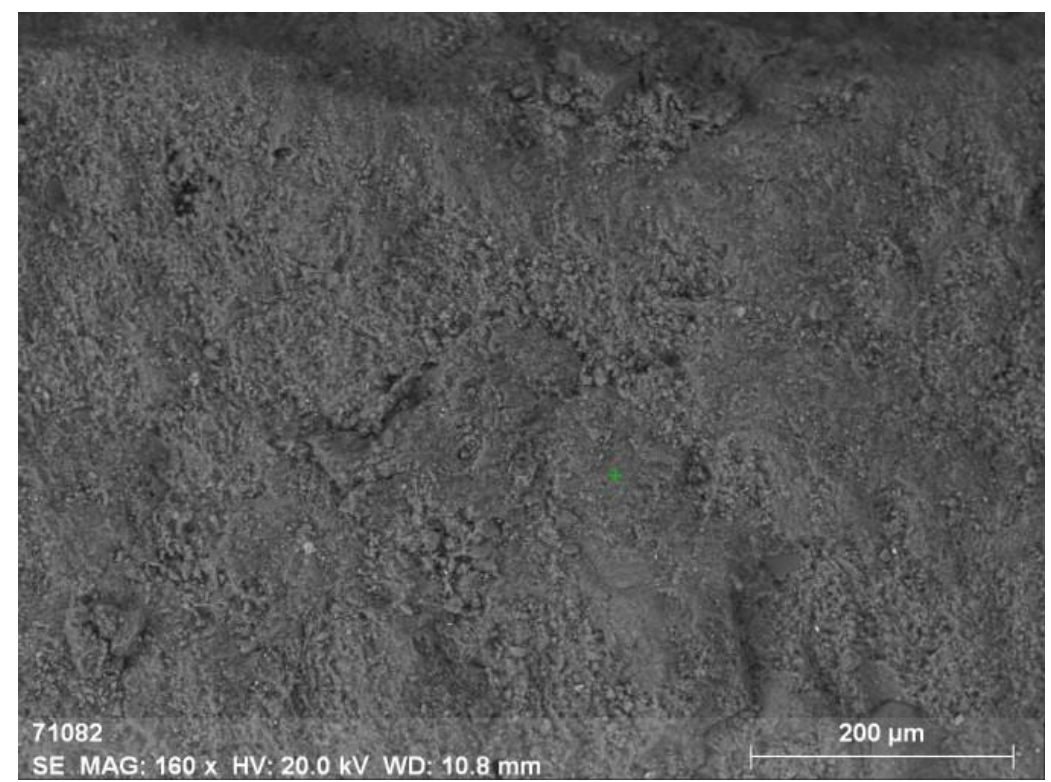

Pис. 1. Поверхность образиа кремнисто-глинистой породы-коллектора

Fig. 1. Surface of a siliceous-clay reservoir rock sample

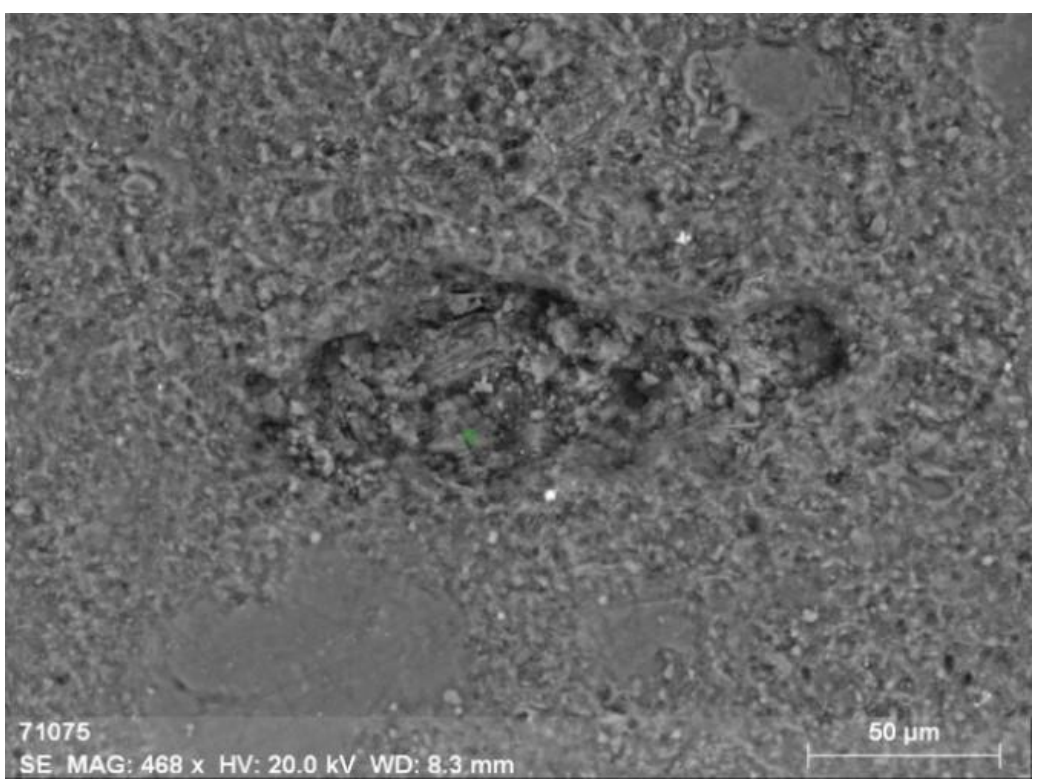

Pис. 2. Мелкая пора, заполненная каолинитом и кварием

Fig. 2. Small pore filled with kaolinite and quartz 


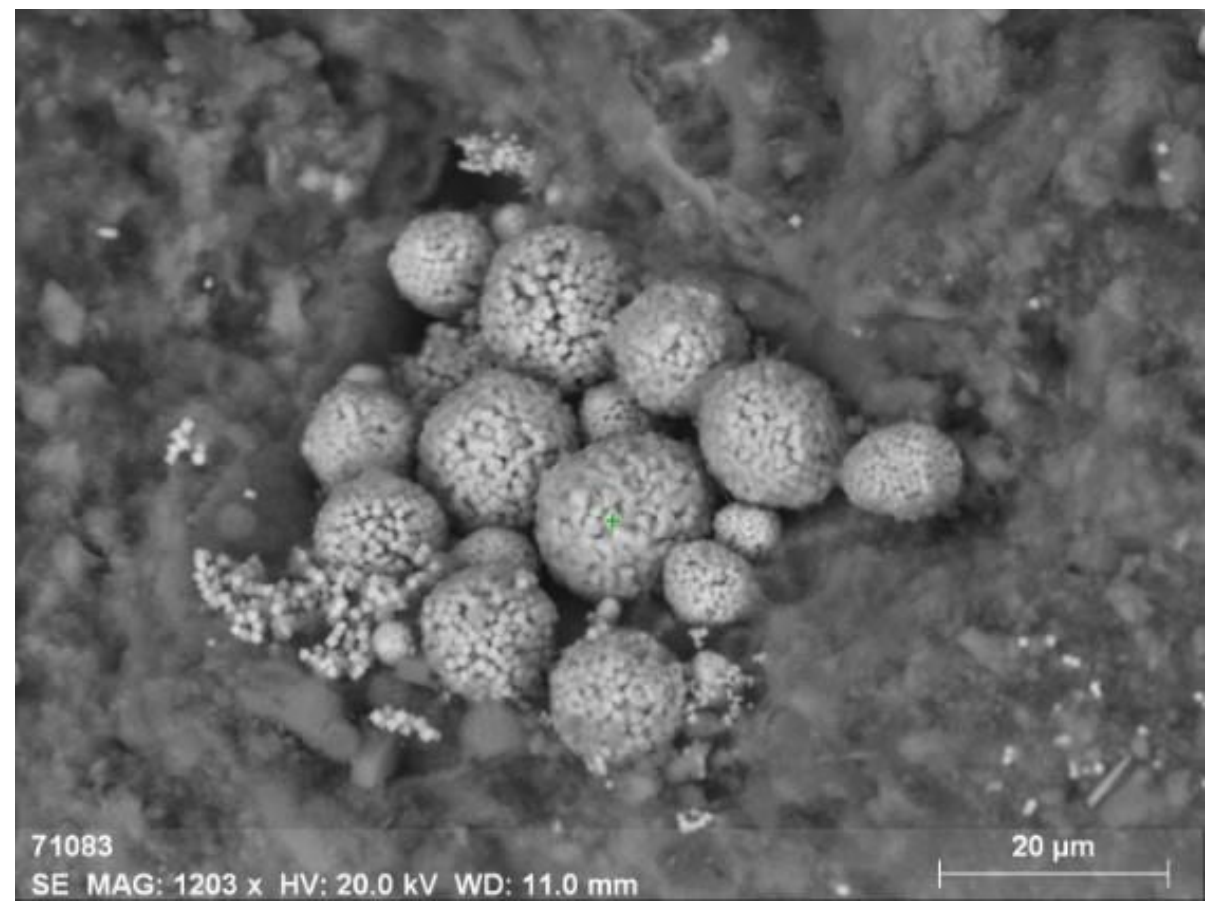

Pис. 3. Фрамбоиды пирита сферической формы, сложноорганизованные агрегаты кристаллитов различного размера Fig. 3. Spherical pyrite framboids and complex aggregates of crystallites of various sizes

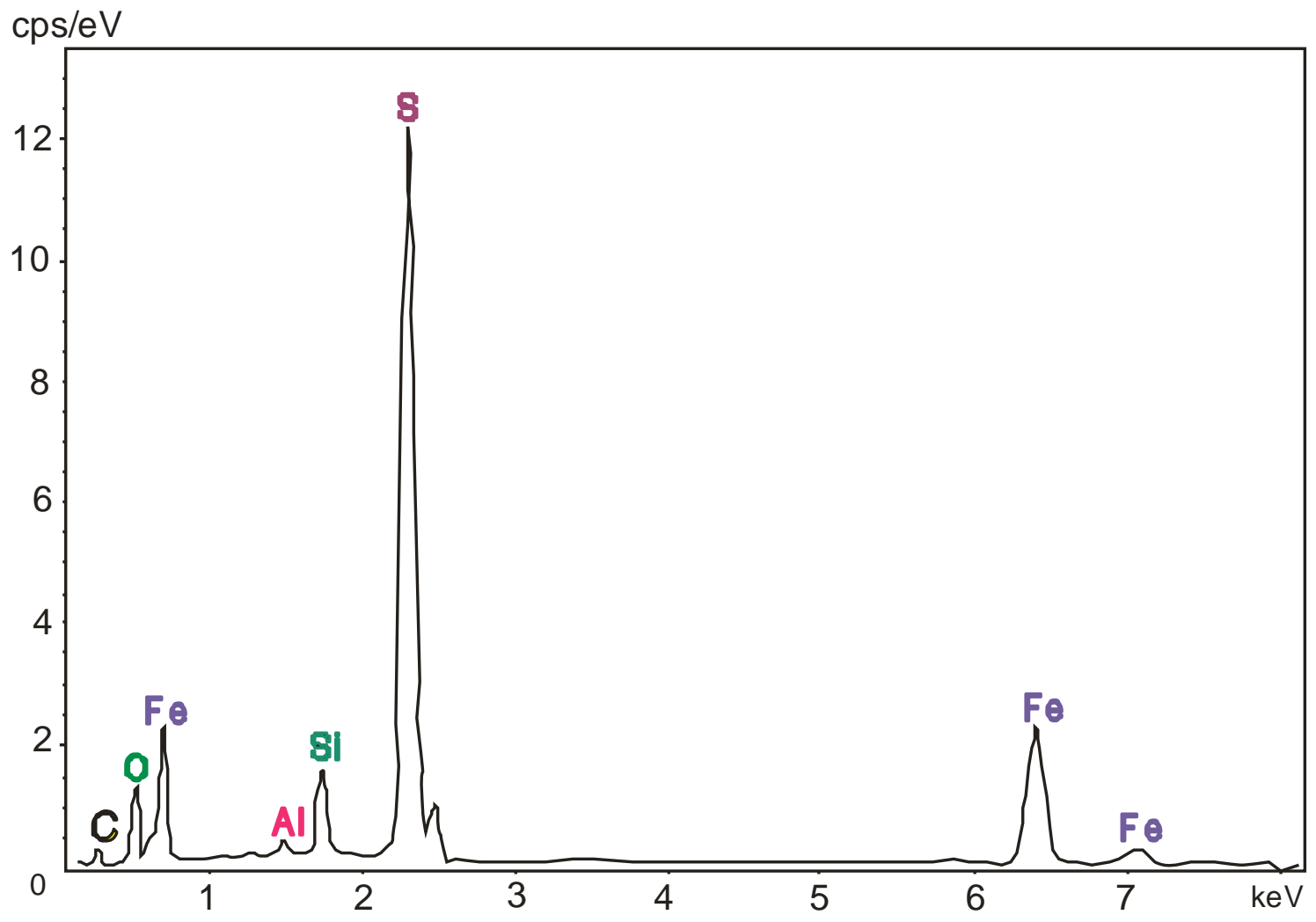

Рис. 4. Элементный состав фрамбоидов пирита

Fig. 4. Elemental composition of pyrite framboids

Хемогенно-биогенное происхождение данных осадочных пород подтверждается встречающимися остатками органического материала: спикул губок, раковин радиолярий, моллюсков и др. (рис. 6), хотя также встречаются терригенные материалы (например, зёрна циркона) и даже моганит [21].
Особое внимание уделено определению кристаллической фазы кварца из аморфной ОКТ-фазы (опала), которая характеризуется повышенной степенью кристалличности кремнисто-глинистых пород-коллекторов и является минералогическим индикатором их повышенной газонасыщенности и проницаемости. 


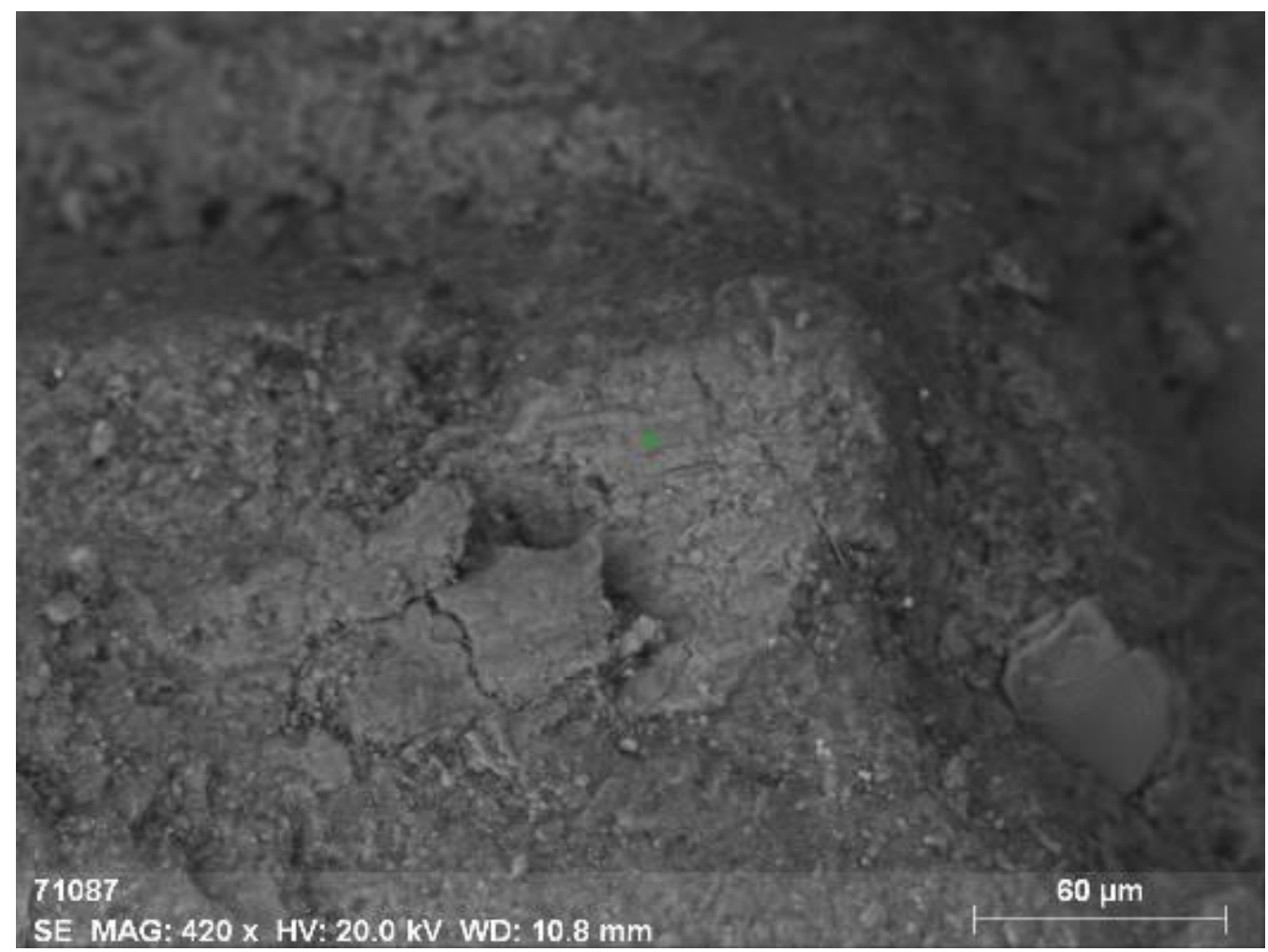

Pис. 5. Зерно монтмориллонита в структуре кремнисто-глинистой породы-коллектора Fig. 5. Grain of montmorillonite in the matrix of a siliceous-clay reservoir rock

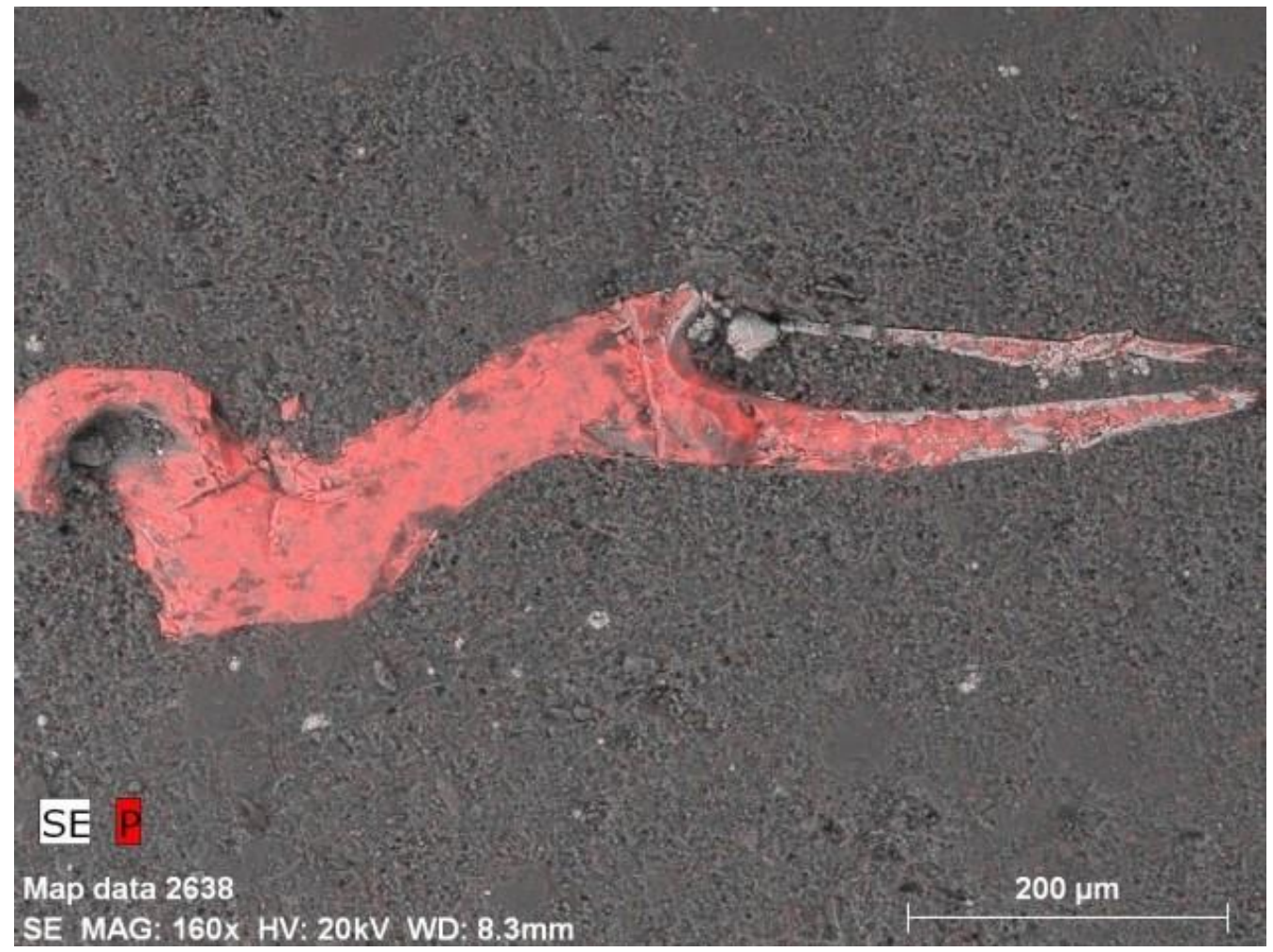

Рис. 6. Фрагмент материала органического происхождения, состоящего преимущественно из апатита

Fig. 6. Fragment of a material of organic origin consisting mainly of apatite

Обнаружение низкотемпературных модификаций кремнезёма стало возможным благодаря современным компьютерным программам обработки рентгенограмм на основе моделирования структур кремнезёма, полу- чаемым методом рентгеновской дифракции (XRD) [25]. На рентгенограммах (рис. 7) наблюдается широкий рефлекс рассеяния рентгеновских лучей в районе углов $2 \theta$ от 20 до $26^{\circ}$ (так называемое «аморфное гало» [26]). 
Следует отметить, что использование обычных приемов рентгенографии для исследования природных образцов с наличием полиморфных модификаций диоксида кремния, слагающих ОКТ-фазу (опалкристобалит-тридимитовая фаза), бывает затрудни- тельным, поскольку между ними нет четких границ, а наблюдаются постепенные переходы от рентгеноаморфного кремнезема до более упорядоченного опалкристобалита и кристаллического тридимита, которые могут иметь разные структурные характеристики.

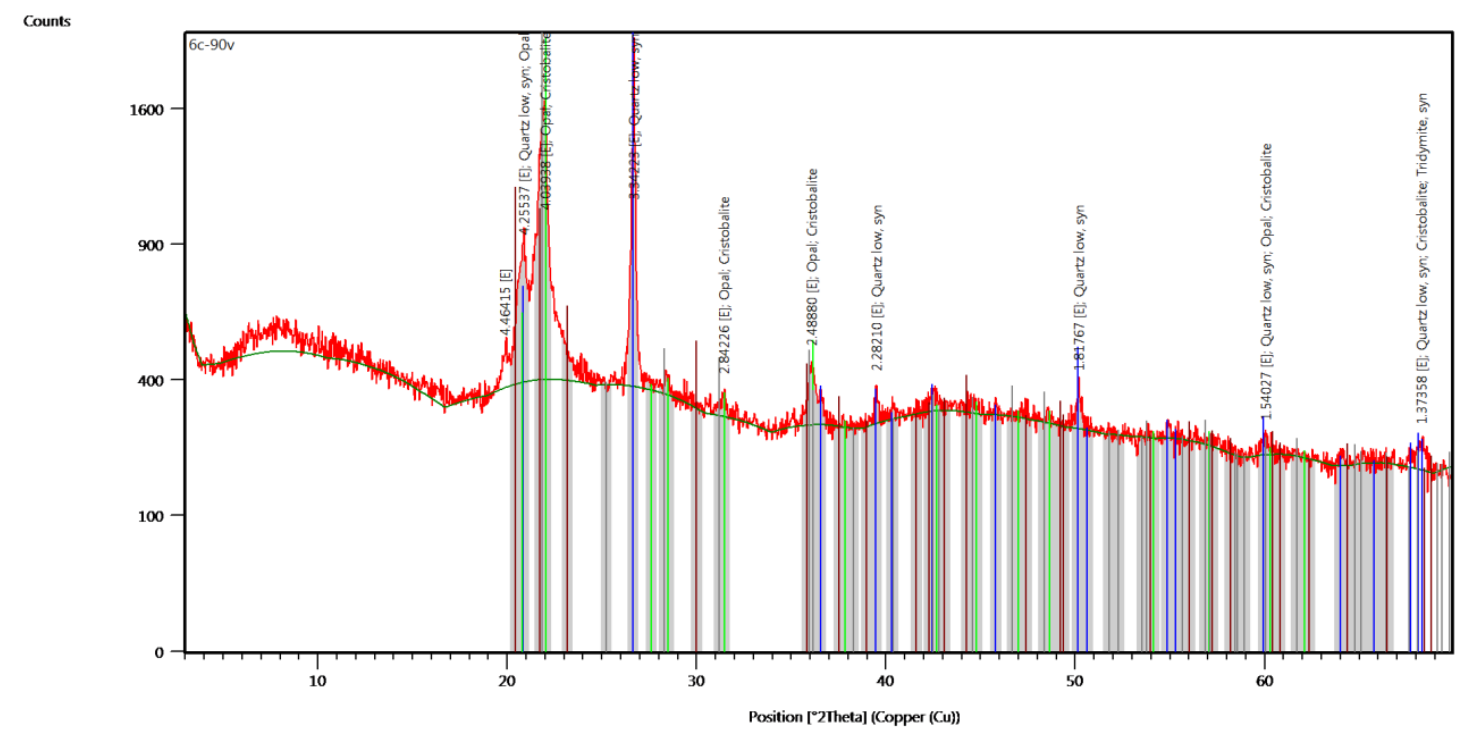

Рис. 7. Рентгенограмма валового состава обр. бс-90. Минеральный состав: квари $\left[3,34_{10} ; 4,25_{2} ; 1,81_{2} A\right]$, опал $\left[4,05-4,07_{10} ; 3,33_{3} \AA\right]$, кристобалит $\left[4,02_{10} ; 2,83_{2} ; 2,45-2,47_{2} \AA\right]$, тридимит $\left[4,30_{10} ; 4,09_{6} ; 3,80_{6} \AA\right]$, глинистые минералы. Цветами отмечено: квари - синий, опал - зеленый, кристобалит - серый, тридимит - темно-красный

Fig. 7. X-ray diffraction pattern of the sample 6s-90. Mineral composition: quartz $\left[3,34_{10} ; 4,25_{2} ; 1,81_{2} \AA\right]$, opal $\left[4,05_{-4,07_{10}}\right.$; $\left.3,33_{3} A\right]$, cristobalite $\left[4,02_{10} ; 2,83_{2} ; 2,45-2,47_{2} \AA\right]$, tridymite $\left[4,30_{10} ; 4,09_{6} ; 3,80_{6} \AA\right]$, clay minerals. Quartz is marked in blue, opal - in green, cristobalite - in gray, tridymite - in dark red

Для оценки степени кристалличности кварца использовался метод инфракрасной (ИК) спектроскопии [20]. Кристаллическая фаза кварца определяется наличием характерного для $\alpha$-кварца двойного пика ИК поглощения в диапазоне 800-778 $\mathrm{cm}^{-1}$ (рис. 8). С изменением степени кристалличности вид данного дублета меняется, и, по мнению И.И. Плюсниной [20], именно его можно использовать для получения относительного критерия оценки кристалличности кварца. Положение двойного пика при 778 и $797 \mathrm{~cm}^{-1}$ по спектру, средняя интенсивность, отсутствие суперпозиции других полос и большая чувствительность к структурным изменениям явились причиной его использования в $[19,27]$ для расчёта индекса кристалличности по формуле

$$
K c i=10 f a / b,
$$

где $a / b$ - отношение величины слабого пика $778 \mathrm{~cm}^{-1}$ к его коротковолновому плечу; $f$ - коэффициент пропорциональности для эталонного кварца, принимаемый в работе [20] равным 2,8; в данной работе использовался выравнивающий коэффициент пропорциональности $f=6$ (рис. 8).

В таблице приведены результаты определения общего минерального состава кремнисто-глинистых пород методом полуколичественного рентгенофазового анализа и значения индекса кристалличности $(\mathrm{Kci})$, рассчитанные по спектрам инфракрасного поглощения. Образцы отобраны по разрезу скважины № 6 Медвежьего месторождения.

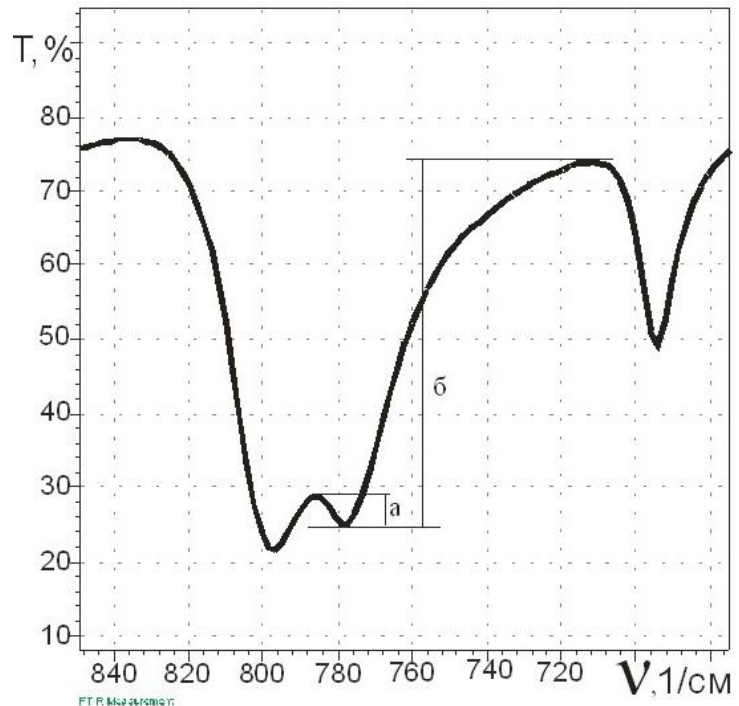

Pис. 8. Пояснение к методике расчёта индекса кристалличности по изменению пиков поглощения $778 \mathrm{~cm}^{-1}$ в спектрах инфракрасного поглощения

Fig. 8. Explanation of the method for calculating the crystallinity index by changing the absorption peaks at $778 \mathrm{~cm}^{-1}$ in the infrared absorption spectra

Значения индекса кристалличности, равные нулю, соответствуют содержанию кристаллической фазы кварца менее 50 \% и характеризуют зоны низкопроницаемых коллекторов, являющихся неперспективными для разработки. Участки кремнисто-глинистых 
пород, характеризующиеся высокими значениями индекса кристалличности, как правило, содержат более 80 \% кварца и могут быть отнесены к числу перспективных зон, поскольку отличаются повышенной про-

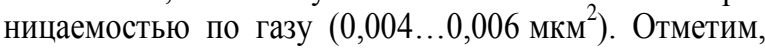
что такие оценки проницаемости были получены на измельчённой до фракции 1...5 мм породе с использованием метода GRI. Литологически сложнопостроенные, неоднородные разрезы закономерно включают в себя и переходные зоны, которые характеризуются переменными интервалами уплотнения и пустотного пространства [5, 28].

Таблица. Результаты определения общего минерального состава кремнисто-глинистых пород методом полуколичественного рентгенофазового анализа и значения индекса кристалличности (Ксі), рассчитанные по спектрам инфракрасного поглощения

Table. $\quad$ Total mineral composition of siliceous-clay rocks determined by semi-quantitative $X$-ray phase analysis and the values of the crystallinity index (Kci) calculated from the infrared absorption spectra

\begin{tabular}{|c|c|c|c|c|c|c|c|c|}
\hline \multirow{3}{*}{$\begin{array}{c}\text { Лабораторный № образца } \\
\text { Sample number }\end{array}$} & \multicolumn{8}{|c|}{ Минералы/Minerals } \\
\hline & \multirow[b]{2}{*}{$\begin{array}{l}\text { Кварц } \\
\text { Quartz }\end{array}$} & \multicolumn{2}{|c|}{ Полевые шпаты/Feldspars } & \multirow[b]{2}{*}{$\begin{array}{l}\text { Сумма глинистых } \\
\text { Amount of clay }\end{array}$} & \multirow[b]{2}{*}{$\begin{array}{l}\text { OKT } \\
\text { OCT }\end{array}$} & \multirow[b]{2}{*}{$\begin{array}{l}\text { Пирит } \\
\text { Pyrite }\end{array}$} & \multirow[b]{2}{*}{$\begin{array}{l}\text { Барит } \\
\text { Barite }\end{array}$} & \multirow[b]{2}{*}{ Kci } \\
\hline & & $\begin{array}{c}\text { КПШ } \\
\text { K- feldspar }\end{array}$ & $\begin{array}{c}\text { NaПШ } \\
\text { Na-feldspar }\end{array}$ & & & & & \\
\hline $6 c-37$ & 67 & 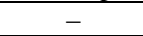 & 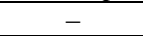 & 23 & 10 & 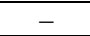 & 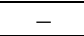 & 8,15 \\
\hline $6 c-90$ & 38 & - & - & 35 & 27 & - & - & 0 \\
\hline $6 c-97$ & 36 & 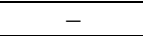 & 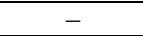 & 30 & 34 & - & 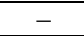 & 0 \\
\hline $6 \mathrm{c}-104$ & 38 & - & - & 32 & 30 & - & - & 0 \\
\hline $6 c-107$ & 53 & - & - & 36 & 11 & сл & - & 1,0 \\
\hline $6 c-153$ & 58 & - & - & 32 & 10 & - & - & 1,22 \\
\hline $6 c-323$ & 84 & - & - & 16 & - & - & - & 8,05 \\
\hline $6 c-372$ & 81 & - & - & 19 & $\begin{array}{l}- \\
-\end{array}$ & - & - & 10,73 \\
\hline
\end{tabular}

Авторы работы [12] считают, что содержание в породе собственно ОКТ-фазы и других минералов (карбонатов, цеолита, глинистых минералов) не влияет на соотношение структурных блоков ОКТ-фазы. Но в работе [13] отмечается, что повышенное содержание смектитов замедляет фазовые превращения в кремнезёме, а присутствие карбонатных минералов, наоборот, может ускорить преобразование в ОКТфазе, что в итоге может вызвать появление неоднородности распределения кристаллического вещества и привести к сложному переплетению последовательности опал-СТ. При интерпретации рентгенограмм следует учитывать не только размеры кристаллитов (тридимита, кристобалита, кварца), но и структурные особенности, связанные с переменным количеством слоёв кристобалита и тридимита и изменением их относительных пропорций [26], и содержанием воды [9]. Сложные процессы диагенеза ОКТ-фазы и вариации фазовых модификаций кремнезёма даже на небольших интервалах зон осадконакопления могут обусловливать изменение расчётных значений содержания фаз и индекса кристалличности. Поэтому, учитывая сложность интерпретации последовательностей фазовых модификаций кремнезёма в кремнистоглинистых отложениях, следует использовать комплекс дополнительных минералогических и геохимических методов [21].

\section{СПИСОК ЛИТЕРАТУРЫ}

1. Проблемы оценки нефтегазоперспективности отложений нижнеберезовской подсвиты севера Западной Сибири / В.В. Черепанов, С.Н. Меньшиков, С.А. Варягов, Д.Ю. Оглодков, В.Л. Бондарев, В.Т. Гудзенко, М.Ю. Миротворский, В.П. Клокова // Геология, геофизика и разработка нефтяных и газовых месторождений. -2015 . - № 2. - С. 11-26.

2. Пережогин А.С., Нежданов А.А., Смирнов А.С. Перспективы освоения сенонского газоносного комплекса севера Западной Сибири // Экспозиция Нефть Газ. - 2016. - № 6. - С. 42-45.

3. Родивилов Д.Б., Кокарев П.Н., Мамяшев В.Г. Газонасыщенность нетрадиционного коллектора нижнеберезовской под-
Не смотря на различные оценки содержания фазовых модификаций кремнезёма, возможно установление некоторых «пороговых» значений индекса кристалличности, позволяющих разделять зоны нетрадиционных коллекторов и оценивать их перспективность.

\section{Заключение}

Доля различных фазовых модификаций кремнезёма существенно меняется по разрезу. Поскольку кристаллическая модификация кремнезёма (кварц) по сравнению с аморфной занимает меньший объём, то, как следствие, вызывает в пласте появление дополнительного пустотного пространства и повышение газонасыщенности и может служить основанием для выделения пластов, что, в свою очередь, является литолого-минералогическим и промыслово-геологическим критерием выявления продуктивных зон в нетрадиционных коллекторах нефти и газа. Выявление особенностей минерального состава низкопроницаемых пород-коллекторов, влияющих на их фильтрационно-емкостные свойства, позволяет оценить перспективность их вовлечения в разработку месторождения, а также будет способствовать решению главной проблемы, возникающей при эксплуатации преобладающего количества газовых месторождений Западно-Сибирской нефтегазоносной провинции, - продление «жизни» месторождений газа после истощения высокопродуктивных сеноманских отложений.

свиты севера Западной Сибири и ее связь с минеральным составом и структурой пустотного пространства // Экспозиция Нефть Газ. - 2018. - № 3 (63). - С. 26-31.

4. Литолого-минералогические и промыслово-геологические критерии выделения продуктивных зон в сенонских отложениях / Д.Я. Хабибуллин, А.Н. Рыбьяков, Н.Р. Ситдиков, С.А. Варягов, С.В. Нерсесов, С.Г. Крекнин, В.В. Огибенин, А.А. Дорошенко, Я.О. Карымова, Д.Б. Родивилов // Геология и разработка месторождений. - 2018. - № 8. - С. 34-41.

5. Дорошенко А.А., Карымова Я.О. Характеристика пустотного пространства опок сенонских отложений севера Западной Сибири // Экспозиция нефть газ. - 2016. - № 6 (69). - С. 23-27. 
6. Identification of components in smectite/kaolinite mixtures / J. Madejová, J. Kečkéš, H. Pálková, P. Komadel // Clay Minerals. 2002. - V. 37 (2). - P. 377-388

7. Madejová J., Komadel P. Baseline studies of the clay minerals society source clays: Infrared methods // Clays and Clay Minerals. - 2001. - V. 49 (5). - P. 410-432.

8. Vu Cong Khang, Korovkin M.V., Ananyeva L.G. Identification of clay minerals in reservoir rocks by FTIR spectroscopy // IOP Conf. Series: Earth and Environmental Science 43. - 2016. - V 43. № 111. - article №012004

9. Varkouhi Sh., Cartwright J.A., Tosca N.J. Anomalous compaction due to silica diagenesis - textural and mineralogical evidence from hemipelagic deep-sea sediments of the Japan Sea // Marine Geology. - 2020. - V. 426. - article № 106204.

10. Jones B., Renaut R.W. Microstructural changes accompanying the opal-A to opal-CT transformation: new evidence from the siliceous sinters of Geysir, Haukadalur, Iceland // Sedimentology. - 2007. - V. 54. - № 4. - P. 921-949.

11. Смирнов П.В. Фазовые переходы кремнезема в опалкристобалитовых породах как фактор качества кремнистого сырья // Известия Томского политехнического университета Инжиниринг георесурсов. - 2017. - Т. 328. - № 9. - С. 6-15.

12. Ильичева О.М., Наумкина Н.И., Лыгина Т.З. Фазовое и структурное разнообразие осадочных кремнистых пород как основа оценки их качества // Разведка и охрана недр. - 2012. - № 5. C. $50-53$.

13. Weller R., Behl R.J. Physical and mechanical characteristics of the opal-A to opal-CT transition zone: enhanced diatomite permeability from heterogeneous diagenetic embrittlement / Search and Discovery Article. - 2015. - article № 51112.

14. A review of the classification of opal with reference to recent new localities / N.J. Curtis, J.R. Gascooke, M.R. Johnston, A. Pring // Minerals. - 2019. - V. 9 (5). - article № 00299.

15. Elzeai J.M., Odom E., Miles W.J. Distinguishing well-ordered opal-CT and opal-C from high temperature cristobalite by X-ray diffraction // Analytica Chimica Acta. - 1994. - V. 286. - Iss. 1. P. $107-116$.

16. Smith D.K. Opal, cristobalite, and tridymite: noncrystallinity versus crystallinity, nomenclature of the silica minerals and bibliography // Powder Diffraction. - 1997. - V. 13. - P. 2-19.

17. Assessment of quartz materials crystallinity by X-ray diffraction / M.V. Korovkin, L.G. Ananieva, T.S. Nebera, A.A. Antsiferova //
IOP Conf. Series: Materials Science and Engineering 110. 2016. - V. 110. - № 1. - article № 012095.

18. Application of Fourier transform infrared spectroscopy to silica diagenesis: the opal-A to opal-Ct transformation / B. Rice, H. Freund, W.L. Huang, J.A. Clouse // SEPM Journal of Sedimentary Research. - 1995. - V. 65A. - P. 639-647.

19. Calculation of quarzite crystallinity index by infrared absorption spectrum / O.S. Razva, A.M. Anufrienkova, M.V. Korovkin, L.G. Ananjeva, R.N. Abramova // IOP Conference Series: Earth and Environmental Science. - 2014. - V. 21. - P. 1-4.

20. Плюснина И.И. Исследование структурной неупорядоченности халцедонов методом инфракрасной спектроскопии // ДАН CCCP. - 1978. - T. 240. - № 4. - C. 839-842.

21. Gliozzo E. Variations on the silica theme: classification and provenance from Pliny to current supplies // EMU Notes in Mineralogy. - 2019. - V. 20. - Ch. 2. - P. 13-85.

22. Description for $\mathrm{X}$-ray diffractometer $\mathrm{X}$ 'Pert PRO // The Analytical X-ray Company. $-2013 .-20 \mathrm{p}$.

23. Шатова М.Н., Коровкин М.В. Определение минерального состава палеозойских отложений нефтегазоконденсатного месторождения методом инфракрасной спектроскопии // Булатовские чтения. - 2017. - Т. 2 - С. 308-312.

24. Рейхард Л.Е. Фрамбоиды пирита в донных осадках Белого моря // Федоровская сессия. - 2014. - С. 62-64.

25. Guthrie G.D., Dish D.L. Jr., Reynolds R.C. Modeling the X-ray diffraction pattern of opal-CT // American Mineralogist. - 1995. V. 80. - P. 869-872.

26. Nano-structure of the cristobalite and tridymite stacking sequences in the common purple opal from the Gevrekseydi deposit, Seyitömer-Kütahya, Turkey / M. Hatipolu, Y. Kibici, G. Yanık, C. Özkul, Y. Yardımcı // Oriental Journal of Chemistry. - 2015. V. 31. - № 1. - P. 35-49.

27. Коровкин М.В., Ананьева Л.Г., Анциферова А.А. Оценка степени преобразования кварцитов методом инфракрасной спектрометрии // Известия Томского политехнического университета. - 2012. - Т. 320. - № 1. - С. 16-18.

28. Salih Muhammad Awadha, Zaher MundherYaseenb Investigation of silica polymorphs stratified in siliceous geode using FTIR and XRD methods // Materials Chemistry and Physics. - 2019. V. 228. - P. $45-50$.

Поступила: 02.09.2021 2.

\section{Информация об авторах}

Ананьева Л.Г., кандидат геолого-минералогических наук, доцент отделения геологии Инженерной школы природных ресурсов, Национальный исследовательский Томский политехнический университет.

Дорошенко А.A., доктор геолого-минералогических наук, главный научный сотрудник лаборатории подсчёта запасов ООО «Газпром ВНИИГАЗ».

Ильенок С.C., кандидат геолого-минералогических наук, ассистент отделения геологии Инженерной школы природных ресурсов, Национальный исследовательский Томский политехнический университет.

Kapb.мова Я.О., кандидат геолого-минералогических наук, научный сотрудник лаборатории подсчёта запасов ООО «Газпром ВНИИГАЗ».

Коровкин М.В., доктор физико-математических наук, старший научный сотрудник, профессор отделения нефтегазового дела Инженерной школы природных ресурсов, Национальный исследовательский Томский политехнический университет; профессор факультета инновационных технологий, Национальный исследовательский Томский государственный университет.

Максимова Ю.А., старший преподаватель отделения нефтегазового дела Инженерной школы природных ресурсов, Национальный исследовательский Томский политехнический университет.

Пестерев A.B., кандидат физико-математических наук, научный сотрудник испытательной научноинновационной лаборатории «Буровые промывочные и тампонажные растворы», Национальный исследовательский Томский политехнический университет.

Процкий О.Н., студент отделения нефтегазового дела Инженерной школы природных ресурсов, Национальный исследовательский Томский политехнический университет.

Савинова O.B., кандидат геолого-минералогических наук, доцент отделения геологии Инженерной школы природных ресурсов, Национальный исследовательский Томский политехнический университет.

Xрущева M.O., аспирант Национального исследовательского Томского государственного университета. 
UDC 553.9:549.02

\section{FEATURES OF MINERAL COMPOSITION OF LOW-PERMEABLE SILICEOUS-CLAY RESERVOIR ROCKS FROM THE BEREZOVSKAYA FORMATION IN THE NORTH OF WESTERN SIBERIA}

\section{Lyudmila G. Ananyeva ${ }^{1}$, lga@tpu.ru}

Alexandr A. Doroshenko²,
ssdoro.47@mail.ru, a.doroshenko@nedra.gazprom.ru

Sergey S. llenok', ilenokss@tpu.ru

Yana 0. Karymova², ya.karymova@nedra.gazprom.ru Michail V. Korovkin ${ }^{1,3}$,
mvk@tpu.ru

1 National Research Tomsk Polytechnic University, 30, Lenin avenue, Tomsk, 634050, Russia.

2 "Gazprom VNIIGAZ», 70, Gertsen street, Tyumen, 625000, Russia.

3 National Research Tomsk State University, 36, Lenin avenue, Tomsk, 634050, Russia.

\author{
Yulia A. Maksimova1, \\ yam3@tpu.ru
}

\author{
Alexey V. Pesterev', \\ pesterev@tpu.ru
}

Oleg N. Protsky ${ }^{1}$, onp6@tpu.ru

\section{Olesya V. Savinova ${ }^{1}$, logvinenkoov@tpu.ru \\ Maria O. Khrushcheva ${ }^{3}$, masha2904@mail.ru}

The relevance of the study is caused by the need to develop the oil and gas industry in Western Siberia by identifying unconventional (including low-permeability) reservoirs and assessing their prospects for development.

The aim: to increase the efficiency of gas production by studying the influence of the structure of the mineral substance of rocks on the pore space and identifying unconventional reservoirs.

Objects: Senonian deposits, the commissioning of which is planned to support production in the gas industry.

Methods: optical and electron scanning microscopy, $X$-ray spectral and $X$-ray fluorescence analysis, Infrared spectroscopy, $X$-ray diffraction, analysis of filtration-capacitive properties by the GRI-SMP-200 method.

Results. The features of the mineral composition of low-permeable siliceous-clay reservoir rocks of the Berezovskaya formation in the north of Western Siberia are studied on the example of the Medvezhye deposit. The chemogenic-biogenic origin of these sedimentary rocks is confirmed by the remnants of organic material: sponge spicules, radiolarian shells, mollusks, etc. The rock structure reveals small pores filled with kaolinite and quartz, and individual grains of montmorillonite. Also, there are numerous spherical aggregates of framboid pyrite ( $\left.F e S_{2}\right)$, which is an autigenic early-diagenetic biomineral and characterizes the reduction zone of diagenesis. It is shown that the "crystallinity index» which characterizes the degree of transformation of the opal-cristobalite-tridimite phase (OCT-phase) of silica can be chosen as a lithological and mineralogical criterion for identifying productive zones in unconventional reservoirs of the Medvezhye deposit. The appearance of the crystalline phase of quartz from unstable chemogenic-biogenic amorphous silica causes the appearance of larger voids, increasing gas saturation and gas permeability.

\section{Key words:}

Reservoir rocks, quartz, opal-cristobalite-tridymite phase, polymorphic modifications of $\mathrm{SiO}_{2}$, opal-cristobalite-tridymite phase of silica, Infrared spectroscopy, X-ray structural analysis.

\section{REFERENCES}

1. Cherepanov V.V., Menshikov S.N., Varyagov S.A., Oglodkov D.Yu., Bondarev V.L., Gudzenko V.T., Mirotvorskiy M.Yu., Klokova V.P. Problems of assessing the oil and gas potential of deposits of the Lower Berezovskaya sub-formation of the north of Western Siberia. Geologiya, geofizika i razrabotka neftyanykh i gazovykh mestorozhdeniy, 2015, no. 2, pp. 11-26. In Rus.

2. Perezhogin A.S., Nezhdanov A.A., Smirnov A.S. Prospects for the development of the Senon gas-bearing complex in the north of Western Siberia. Ekspozitsiva Neft Gaz, 2016, no. 6, pp. 42-45. In Rus.

3. Rodivilov D.B., Kokarev P.N., Mamyashev V.G. Gas saturation of the unconventional reservoir of the Lower Berezovskaya subformation of the north of Western Siberia and its relationship with the mineral composition and structure of the void space. Ekspozitsiya Neft Gaz, 2018, no. 3 (63), pp. 26-31. In Rus.

4. Khabibullin D.Ya., Rybyakov A.N., Sitdikov N.R., Varyagov S.A. Nersesov S.V., Kreknin S.G., Ogibenin V.V., Doroshenko A.A., Karymova Ya.O., Rodivilov D.B. Lithological-mineralogical and commercial-geological criteria for the allocation of productive zones in the Senonian sediments. Geologiya $i$ razrabotka mestorozhdeniy, 2018, no. 8, pp. 34-41. In Rus.

5. Doroshenko A.A., Karymova Ya.O. Characteristics of the void space of the salica clay of Senon deposits from the north of Western Siberia. Ekspozitsciya neft gaz, 2016, no. 6 (69), pp. $23-$ 27. In Rus.

6. Madejová J., Kečkéš J., Pálková H., Komadel P. Identification of components in smectite/kaolinite mixtures. Clay Minerals, 2002, vol. 37 (2), pp. 377-388.

7. Madejová J., Komadel P. Baseline studies of the clay minerals society source clays: Infrared methods. Clays and Clay Minerals, 2001, vol. 49 (5), pp. 410-432.

8. Vu Cong Khang, Korovkin M.V., Ananyeva L.G. Identification of clay minerals in reservoir rocks by FTIR spectroscopy. IOP Conf. Series: Earth and Environmental Science, 2016, vol 43, no. 111, article no. 012004

9. Varkouhi Sh., Cartwright J.A., Tosca N.J. Anomalous compaction due to silica diagenesis - Textural and mineralogical evidence 
from hemipelagic deep-sea sediments of the Japan Sea. Marine Geology, 2020, vol. 426, article no. 106204

10. Jones B., Renaut R.W. Microstructural changes accompanying the opal-A to opal-CT transformation: new evidence from the siliceous sinters of Geysir, Haukadalur, Iceland. Sedimentology, 2007, vol. 54, no. 4, pp. 921-949.

11. Smirnov P.V. Phase transitions of silica in opal-cristobalite rocks as a quality factor of siliceous raw materials. Bulletin of the Tomsk Polytechnic University. Geo Assets Engineering, 2017, vol. 328, no. 9, pp. 6-15. In Rus.

12. Ilicheva O.M., Naumkina N.I., Lygina T.Z. Fazovoe i strukturnoe raznoobrazie osadochnykh kremnistykh porod kak osnova otsenk ikh kachestva [Phase and structural diversity of sedimentary siliceous rocks as a basis for assessing their quality]. Razvedka $i$ okhrana nedr, 2012, no. 5, pp. 50-53.

13. Weller R., Behl R.J. Physical and mechanical characteristics of the opal-A to opal-CT transition zone: enhanced diatomite permeability from heterogeneous diagenetic embrittlement. Search and Discovery Article, 2015, article no. 51112.

14. Curtis N.J., Gascooke J.R., Johnston M.R., Pring A. A review of the classification of opal with reference to recent new localities. Minerals, 2019, vol. 9 (5), article no. 00299.

15. ElzeaI J.M., Odom E., Miles W.J. Distinguishing well-ordere opal-CT and opal-C from high temperature cristobalite by X-ray diffraction. Analytica Chimica Acta, 1994, vol. 286, Iss. 1, pp. 107-116.

16. Smith D.K. Opal, cristobalite, and tridymite: noncrystallinity versus crystallinity, nomenclature of the silica minerals and bibliography. Powder Diffraction, 1997, vol. 13, pp. 2-19.

17. Korovkin M.V., AnanIeva L.G., Nebera T.S., Antsiferova A.A. Assessment of quartz materials crystallinity by $\mathrm{x}$-ray diffraction IOP Conf. Series: Materials Science and Engineering, 2016, vol.110, no. 1, article no. 012095 .

18. Rice B., Freund H., Huang W.L., Clouse J.A. Application of Fourier transform infrared spectroscopy to silica diagenesis: the opal-A to opal-Ct transformation. SEPM Journal of Sedimentary Research, 1995, vol. 65A, pp. 639-647.
19. Razva O.S., Anufrienkova A.M., Korovkin M.V., Ananjeva L.G., Abramova R.N. Calculation of quarzite crystallinity index by infrared absorption spectrum. IOP Conference Series: Earth and Environmental Science, 2014, vol. 21, pp. 1-4.

20. Plyusnina I.I. Issledovanie strukturnoy neuporyadochennosti khaltsedonov metodom infrakrasnoy spektroskopii [Investigation of the structural disorder of chalcedony by infrared spectroscopy]. DAN SSSR, 1978, vol. 240, no. 4, pp. 839-842.

21. Gliozzo E. Variations on the silica theme: classification and provenance from Pliny to current supplies. EMU Notes in Mineralogy, 2019, vol. 20, Ch. 2, pp. 13-85.

22. Description for X-ray diffractometer X'Pert PRO. The Analytical $X$-ray Company, 2013, pp. 20

23. Shatova M.N., Korovkin M.V. Determination of the mineral composition of Paleozoic deposits of an oil and gas condensate field by infrared spectroscopy. Bulatovskie chteniya, 2017, pp. 308-312. In Rus.

24. Reykhard L.E. Framboydy pirita $\mathrm{v}$ donnykh osadkakh Belogo moray [Pyrite framboids in the bottom sediments of the White Sea]. Fedorovskaya sessiya, 2014, pp. 62-64.

25. Guthrie G.D., Dish D.L. Jr., Reynolds R.C. Modeling the X-ray diffraction pattern of opal-CT. American Mineralogist, 1995, vol. 80, pp. 869-872

26. Hatipolu M., Kibici Y., Yanık G., Özkul C., Yardimci Y. Nanotructure of the cristobalite and tridymite stacking sequences in the common purple opal from the Gevrekseydi deposit, SeyitömerKütahya, Turkey. Oriental Journal of Chemistry, 2015, vol. 31, no. 1 , pp. $35-49$.

27. Korovkin M.V., Ananeva L.G., Anciferova A.A. Estimation of the degree of transformation of quartzites by infrared spectrometry. Bulletin of the Tomsk Polytechnic University. Geo Assets Engineering, 2012, vol. 320, no. 1, pp. 16-18. In Rus.

28. Salih Muhammad Awadha, Zaher MundherYaseenb. Investigation of silica polymorphs stratified in siliceous geode using FTIR and XRD methods. Materials Chemistry and Physics, 2019, vol. 228, pp. $45-50$.

Received: 2 September 2021.

\section{Information about the authors}

Lyudmila G. Ananyeva, Cand Sc., associate professor, National Research Tomsk Polytechnic University.

Alexandr A. Doroshenko, Dr. Sc., chief researcher, «Gazprom VNIIGAZ».

Sergey S. Ilenok, Cand Sc., associate professor, National Research Tomsk Polytechnic University.

Yana O. Karymova, Cand Sc., researcher, «Gazprom VNIIGAZ».

Michail V. Korovkin, Dr. Sc., professor, senior researcher, National Research Tomsk Polytechnic University, 30, Lenin avenue, Tomsk, 634050, Russia; professor, National Research Tomsk State University.

Yulia A. Maksimova, senior lecturer, National Research Tomsk Polytechnic University.

Alexey V. Pesterev, Cand. Sc., researcher, National Research Tomsk Polytechnic University.

Oleg N. Protsky, student, National Research Tomsk Polytechnic University.

Olesya V. Savinova, Cand. Sc., associate professor, National Research Tomsk Polytechnic University.

Maria O. Khrushcheva, postgraduate student, National Research Tomsk State University. 